DOI: https://doi.org/10.47405/mjssh.v6i8.913

\begin{tabular}{|c|c|}
\hline 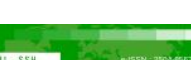 & Malaysian Journal of Social Sciences and Humanities (MJSSH) \\
\hline Malaysian Journal of & Volume 6, Issue 8, August 2021 \\
\hline (MJ-SSH) & e-ISSN : 2504-8562 \\
\hline & $\begin{array}{l}\text { Journal home page: } \\
\text { www.msocialsciences.com }\end{array}$ \\
\hline
\end{tabular}

\title{
Unbreakable Babu Culture and Commercial Sex Workers (CSWs) at Kandapara sex establishment, Bangladesh
}

\author{
Israt Eshita Haque1, Naim Ahamed ${ }^{2}$, Md. Sabbir Hossain ${ }^{3}$ \\ ${ }_{1}^{1}$ Department of Sociology, Noakhali Science and Technology University, Noakhali-3814, Bangladesh \\ 2WASH, HCMP, BRAC, Bangladesh \\ ${ }^{3}$ Department of Forestry and Environmental Science, Shahjalal University of Science and Technology, Sylhet-3114, \\ Bangladesh
}

Correspondence: Israt Eshita Haque (eshita.soc@nstu.edu.bd)

\begin{abstract}
The commercial sex trade with babu culture is a ubiquitous business that itself stands in an embarrassing platform, especially in a predominantly Islamic country like Bangladesh. This study aims to excavate the concept of commercial sex workers and unbreakable babus, the reasons for entering sex establishment, and also the perceptions about themselves for understanding and developing a meaningful relationship. The qualitative method was predominance for its nature and subject matter where in-depth interviews were carried out at Kandapara sex establishment in Tangail, Bangladesh. This study found that socio-demographic and economic factors badly influence them to attach to sex establishment. For commercial sex workers, both voluntary and involuntary factors are responsible to enter the sex establishment, alternatively, only voluntary factors are responsible for babus. This study also found that there are multi-dimensional and diverse perceptions among commercial sex workers and unbreakable babus about their fixed sex partners. The study also addressed taking initiatives for improving their social status in society and emphasizing the further implications of the research.
\end{abstract}

Keywords: commercial sex worker, unbreakable babu, prostitution, a sex establishment, brothel, sex trade

\section{Introduction}

The issue regarding commercial sex work is not a new one. The commercial sex trade is an omnipresent and universal business in the whole world. Nevertheless, the factors, reasons, processes, conditions, trends, and characteristics of commercial sex workers vary from country to country, region to region, society to society, and era to era. In the face of being a global phenomenon, commercial sex work is synonymous in nature with exploitation and stigma in Bangladesh. Commercial sex workers considered as 'immoral beings' confront multiple forms of deprivation and they are awfully marginalized in society (Uk Essays, 2016).

The country itself stands in a confusing and embarrassing platform regarding the identity of the CSWs though brothel-based sex work is not illegal in Bangladesh (Billah, 2012). Notifying that Bangladesh is predominantly Islamic (In Islamic law, prostitution is prohibited, banned, considered as 'Zina'- Al Israa, 17:32); notwithstanding, prostitution in Bangladesh has been legal since 2000 (Candela \& Aldama, 2015). The babus are closely connected with CSWs. Most of the female sex workers embrace 
the babus at Kandapara sex establishment in Tangail, a northern city of Bangladesh. The babus are considered as an intimate partner, lovers, husbands as well as regular customers who usually live outside the sex establishment. They also used to take money from the sex workers and do sex with them in exchange for security in this male-dominated society. In a patriarchal position of male, 'A Bandha Babu' or a regular customer is regarded as a father of the sex worker's children (Mahtab, Haque, Khan, Islam, \& Wahid, 2018). This study wants to examine the ample representation of the unbreakable 'Babu culture' in a sex establishment and its affinity and connectivity with commercial sex workers in Bangladesh. This study also aims to point out that, what does 'the Babus' mean and what are the underlying causes of babus going to a sex establishment.

Sex work is a highly stigmatized and risky activity especially for Asian women that is closely related to the Bangla term 'izzat' or honor. There are wide ranges of socio-cultural, demographic and economic factors influencing female sex workers to enter into sex work. Economic hardship is considered as the main cause for women's entry into sex work in India. However, very few studies have examined how and why commercial sex workers choose for entering brothels to maintain their livelihood, even though the women are fully aware of the risks and dangers associated with being involved in the sex industry (Sinha, 2015). However, good numbers of works about commercial sex workers have already been done, but previous studies have failed to articulate real reasons of a woman for entering into a sex establishment as commercial sex workers (CSWs) in society. This study tries to fill the gap in the literature by investigating the underlying causes and factors influencing a woman for entering the sex establishment as CSWs from the Bangladesh perspective.

Very limited studies have been conducted to investigate the relationship between CSWs and the unbreakable babu culture in society. The study tries to explore the perception of commercial sex workers (CSWs) about the babus and also the perceptions of the babus about CSWs in Bangladesh. The findings can be helpful to develop a clear conceptualization of the babu culture in the society, to examine the causation of entering women into commercial sex work, and to explore the perceptions of the babu about CSWs and vice-versa. This study also can be used for making it possible to develop programs for commercial sew workers and to protect human rights in any given environment.

The objective of this paper is to examine the ample representation of the unbreakable babu culture and its affinity and connectivity with commercial sex workers in Bangladesh. This study tries to represent certain socio-demographic profiles of the babus and commercial sex workers (CSWs) in the sex establishment. Getting explicit concepts about the babu culture in Bangladesh society and also about CSWs in the sex establishment is another significant purpose of this study. There are diverse reasons for entering a sex establishment among CSWs and Babus. Moreover, this study tries to investigate the underlying causes of entering the sex establishment as 'CSWs' and as 'Babus' in Bangladesh. The multidimensional perceptions of CSWs about babus and vice-versa are also an important objective in this study.

\section{Literature Review and Conceptual Framework}

\section{Commercial Sex Workers}

Sex is the cheapest commodity, and sex-workers are considered as the worst form of human beings in Third-world Muslim countries like Bangladesh though sometimes it holds many double standards. Sexuality is a highly sensitive and complicated agenda in where 'sex-work' and 'sex worker' is as per usual defined as the exchange of sexual services for cash and/or other material benefits and are less stigmatizing than the term 'prostitute' (Karim, 2004). Sex workers are women, men, and transgendered people who receive money or goods in exchange for sexual services or, sexual stimulation, gratification, or also other sex acts and who consciously define those activities as income generating even if they do not consider sex work as their occupation. Besides, Commercial sex is the exchange of money or goods for sexual services involving a sex worker and a client and frequently also involves a third party (Overs, 2002). 
However, in this article, the term 'Commercial sex worker' is used by the author that is also conterminous to the term 'Sex workers'. Commercial sex workers are those who are engaging in sexual practices and activities to earn money or other financial or economic benefits (Farlex, 2009). Nevertheless, commercial sexual workers involve in many commercial sexual activities such as sexually explicit performances, prostitution, and participation in the production of pornography, performance in a strip club, or exotic dancing or display in which resources are exchanged and also anything of value is given to or received by any person (Law Insider Dictionary, 2013).

\section{Babu Culture}

In the 19th century Bengal, the profession of prostitution (who were known as 'beshyas' in Bengali) occupying a socio-economic position of deprivation and humiliation in society experienced a change with the introduction of new commercial and administrative relations and also acquiring new types of clientele. The clientele was known as the 'babus' in the utterance of the red-light areas. The babus considered the sex workers as a regular nocturnal fantasy of pleasure (Banerjee, 1993).

In the 21st century, the babus are closely related to commercial sex workers in brothel-based prostitution. It was mentioned before that the babus are referred to as an intimate partner, lovers, husbands as well as regular customers who normally live outside the sex establishment occasionally taking money and sex from them in exchange for security in this male-dominated society. In a patriarchal position of male, 'A Bandha Babu' or a regular customer is regarded as a father of the sex worker children (Mahtab, Haque, Khan, Islam, \& Wahid, 2018). Although commercial sex-work in Bangladesh has always existed and taken many changing forms, it remained ignored, avoided, and rather un-researched by social scientists till recently. However, there have been great possibilities in studying this issue (Karim, 2004).

The problem of identity of the commercial sex workers with unbreakable babus culture in Bangladesh is itself a conceptual problem and debatable issue. In many previous types of research, good numbers of works have already been done on this topic, but in diverse perceptions. In this research, commercial sex workers (CSWs) have been considered as sex workers who are working as prostitution by selling their bodies in exchange for money and also noted that all commercial sex workers are female. They all are staying at Kandapara sex establishment in Tangail, a northern city of Bangladesh.

Most of the sex workers embrace the babus. Babus have been considered in this research as intimate partners or lovers and sometimes unauthorized husband. Therefore, the perception of babus by CSW and the perception of CSWs by babus have diverse conceptions. However, conceptualizing the unbreakable babus and CSWs will be very considerable work to know the real picture about sex embellishment in society.

\section{Conceptual Framework}

The below conceptual framework shows that CSWs of this study are working as with only one identified as 'prostitution' and all respondents of CSWs are females who are engaging sexual practice and activities by selling their body in exchange of money. Furthermore, Babus conceptualizes as more than clients in a sex establishment and have been claimed by the CSWs as an unauthorized husband, intimate partner, lovers, and also a regular loving customer. Besides, all respondents of unbreakable babus are male and are living outside the sex establishment.

Moreover, the conceptual framework also represents the unbreakable Babu culture and its affinity and connectivity with CSWs and also the relational discourses including the socio-demographic situation of the babus and CSWs, underlying reasons for entering the sex establishment as 'Commercial Sex Worker' and as 'Babus', the perception of CSWs about babus and vice-versa in Bangladesh. 
Figure 1: Conceptual Framework of the study

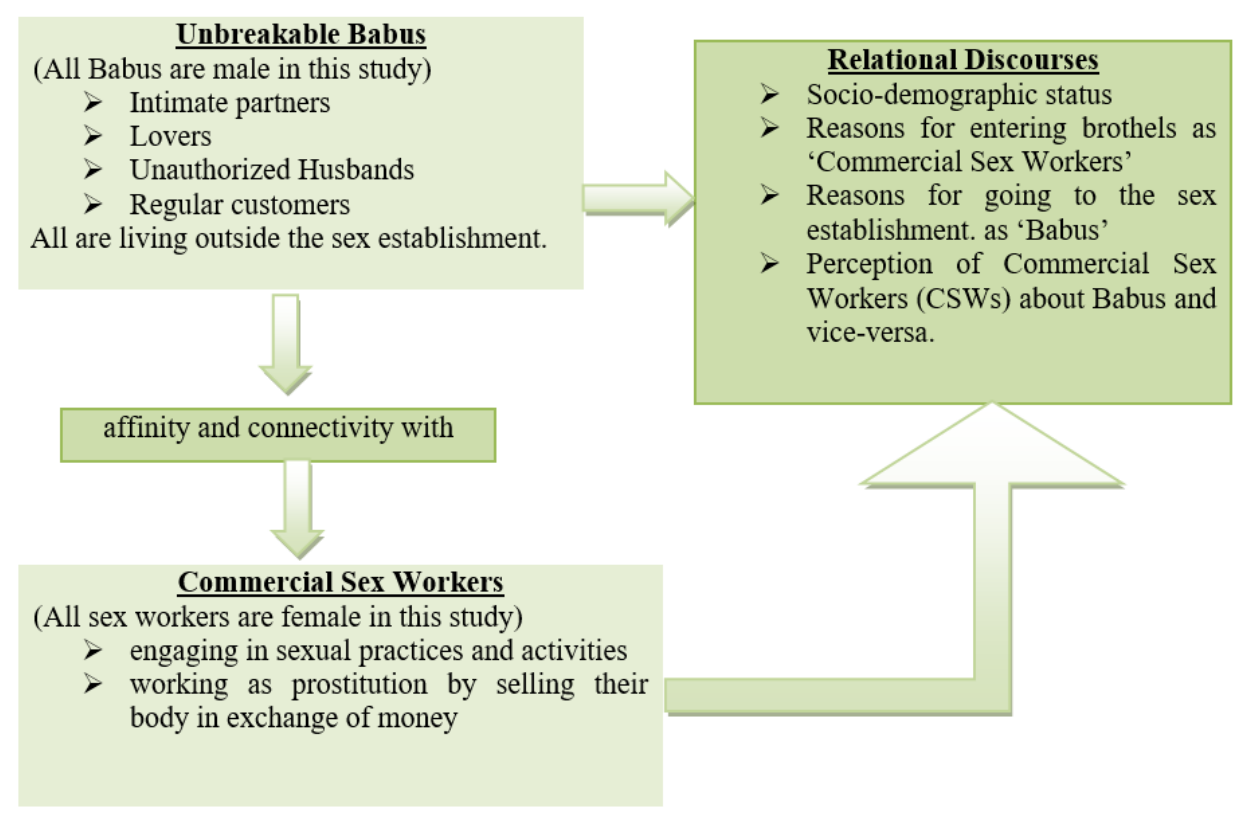

\section{Methodology}

Because of the sensitivity and complicated issue of commercial sex workers concerning unbreakable Babu Culture, the qualitative method was predominant in the research. Judgmental sampling was used in this study where a total of twenty (20) respondents were selected among them ten (10) were commercial sex workers and the other ten (10) were babu living at kandapara sex establishment in Bangladesh. The oldest brothel founded about 200 years ago named Kandapara brothel has been selected as study area which is situated in the main town of Tangail District of Bangladesh. (Wikipedia).

Figure 2: Map of Kandapara, Tangail Sadar Upazila, Tangail District (The Bangladesh Network)

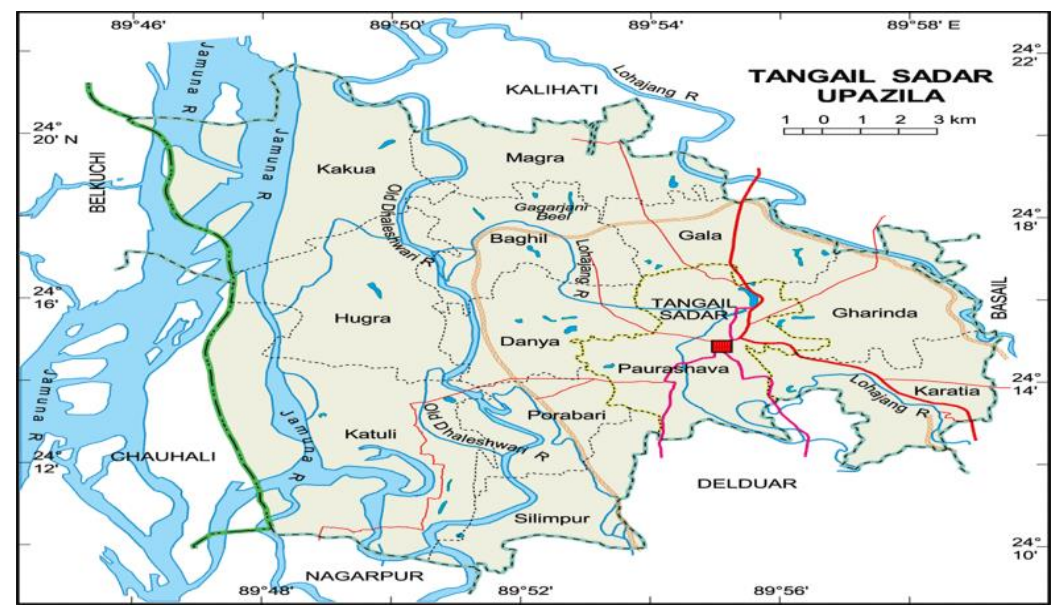

Now a days, the term 'brothel' is not preferred among the sex workers and hence, they prefer to use the term 'sex establishment' instead of 'brothel'; respondents argue that using the term 'sex establishment' is a symbol of promoting their human rights. As a result, the term 'sex establishment' has been deliberately used by the researchers to indicate the alternative meaning of 'brothel' in where a sex establishment means sexual entertainment venue (Breckland Council). 
Moreover, a judgmental sampling also referred to as a purposive sample that can be logically assumed to be representative of the population and often accomplished by applying expert knowledge of the population to select in a nonrandom manner a sample of elements (Lavrakas, 2008). It depends on both primary and secondary sources of data collection. As a qualitative method, in-depth interviews were conducted by using semi-structured interview schedules from December, 2019-March 2020 to have a deeper understanding of the phenomena. Informal conversations, life histories, key informant interviews, and others were also used in the study. $I$

Data had been collected from secondary sources (journals, articles, books, reports unpublished research materials, dissertation, etc.) to supplement the primary data. The study is a mainly interpretative and analytical type of research. Description and explanation of themes and concepts are presented in a narrative way in this study. In the time of conducting research, ethical considerations including voluntary participation, consent of the respondents, right to privacy or confidentiality, etc. had been considered consciously.

\section{Results}

\section{The socio-demographic situation of the Babus and Commercial Sex Workers (CSWs)}

The information gathered from the respondents of the study embedded the cornerstone for this analysis. At the beginning of each case study demographic and socio-economic data were collected extensively from respondents concerning their sex, age, education, marital status, and number of children, monthly income, and so on to analyze the in-depth situation from Bangladesh perspective.

Table 1: Socio-demographic profile of the CSWs

\begin{tabular}{lllllll}
\hline Case studies & Sex & Age & Education & $\begin{array}{l}\text { Marital } \\
\text { Status }\end{array}$ & $\begin{array}{l}\text { Number } \\
\text { of } \\
\text { Children }\end{array}$ & $\begin{array}{l}\text { Monthly } \\
\text { Income }\end{array}$ \\
\hline CSW-1 & Female & 20 & Up to class 3 & Unmarried & 0 & 40,000 \\
CSW -2 & Female & 25 & Up to class 5 & Unmarried & 0 & 44,000 \\
CSW -3 & Female & 40 & Never goes to school & Married & 4 & 25000 \\
CSW -4 & Female & 20 & Never goes to school & Unmarried & 0 & 35000 \\
CSW -5 & Female & 30 & Up to class 9 & Unmarried & 1 & 50000 \\
CSW -6 & Female & 26 & Never goes to school & Married & 1 & 28000 \\
CSW -7 & Female & 23 & Up to class 5 & Unmarried & 1 & 38000 \\
CSW -8 & Female & 28 & Up to S.S.C & Unmarried & 0 & 50000 \\
CSW -9 & Female & 50 & Never goes to school & Married & 2 & 32000 \\
CSW -10 & Female & 20 & Up to class 7 & Unmarried & 0 & 45000
\end{tabular}

\section{Note: CSW= Commercial Sex Worker}

The above table shows the socio-economic and demographic profile of the CSWs staying at Kandapara sex establishment in Tangail, Bangladesh. In the sex and age distribution, all respondents of CSWs are female and among ten case studies eight respondents are aged between 20-30 years and the other twice of 10 are 40years and 50years old. In such an age distribution, the table shows that young sex workers are more prevalent and imperious than the senior sex worker. There is a notable variation in education level, marital status, and also the number of children among the sample respondents selected for the research study. A greater portion of the respondents are underclass eight and among them, four respondents have no idea of a school that means they didn't go to school in their lifetime; surprisingly only one respondent completed Secondary School Certificate (S.S.C) there. A 
maximal portion of the respondents are unmarried and only three are married. The unusual matter here is that two unmarried respondents have one female child and because of their female child they get extra priority with many facilities by Shordarni (Sex worker's leader). Otherwise, three sex workers have children, and the rest of the five have no children. The most engrossing consideration of this study is to get a clear relationship between the socio-demographic profile and economic condition of CSWs. Young age unmarried sex workers with having no children earn more money (average $35000-$ 50000 taka per month) than more senior married with having children (average 25000 - 34000). Remarkable diversity can also be found that relatively educated sex workers earn a good amount of money than illiterate sex workers.

Table-2: Socio-demographic profile of the unbreakable Babus

\begin{tabular}{|c|c|c|c|c|c|c|}
\hline $\begin{array}{l}\text { Case } \\
\text { studies }\end{array}$ & Sex & Age & Education & $\begin{array}{l}\text { Marital } \\
\text { Status }\end{array}$ & $\begin{array}{l}\text { Number } \\
\text { of } \\
\text { Children } \\
\end{array}$ & $\begin{array}{l}\text { Monthly } \\
\text { Income }\end{array}$ \\
\hline Babu-1 & Male & 26 & Primary & Married & 1 & 40,000 \\
\hline Babu-2 & Male & 35 & Honours degree & Married & 2 & 35000 \\
\hline Babu-3 & Male & 45 & Primary & Married & 4 & 55000 \\
\hline Babu-4 & Male & 25 & Secondary & Unmarried & 0 & 45000 \\
\hline Babu-5 & Male & 36 & $\begin{array}{l}\text { H.S.C/Higher } \\
\text { Secondary }\end{array}$ & Married & 3 & 50000 \\
\hline Babu-6 & Male & 28 & Degree & Married & 1 & 30000 \\
\hline Babu-7 & Male & 40 & Honours degree & Married & 2 & 38000 \\
\hline Babu-8 & Male & 55 & $\begin{array}{l}\text { H.S.C /Higher } \\
\text { Secondary }\end{array}$ & Married & 1 & 60000 \\
\hline Babu-9 & Male & 25 & Class eight & Unmarried & 0 & 30000 \\
\hline Babu-10 & Male & 57 & $\begin{array}{l}\text { H.S.C /Higher } \\
\text { Secondary }\end{array}$ & Married & 2 & 55000 \\
\hline
\end{tabular}

The above table shows the socio-economic and demographic profile of the unbreakable babus living outside the sex establishment. In the sex and age distribution, all respondents of babus are male and among ten case studies four respondents are aged between 20-30 years and the other six babus are between 35-57 years old. In such an age distribution, the table shows that relatively older age attach the sex establishment as babus than younger age. There is a notable variation in education level, marital status, and also the number of children among the sample respondents selected for the research study.

The table shows that two babus have completed primary education; only one babu has completed class eight; four respondents completed secondary and higher secondary and the rest of three have completed graduation. Therefore, literate persons are more attached to unbreakable Babu Culture than illiterate persons. The maximal portion of the respondents is married with having children and only two are unmarried with no children. Per month, six respondents earn between 40,000 -60,000 taka and the other four respondents earn between 30,000 - 40,000 taka. The observable issue here is that married babus with having children and a good amount of monthly income is more attached to sex workers as their babus than unmarried babus with having no children and low monthly income. Though clients and non-clients of sex workers did not differ on key socio-demographic as well as economic variables such as age, education, marital status, monthly income, or whether they had children of their own but differed significantly on sex-role orientation, sensation seeking, and socialsexual effectiveness (Xantidis, Psych, \& P. McCabe, 2000). Hence, the socio-demographic and economic backgrounds of the respondents differ remarkably and also vary to enter a sex establishment that can be analyzed from different points of view. 


\section{Underlying reasons for entering the sex establishment as 'Commercial Sex Worker' and as 'Babus'}

The sex trade is still being conducted covertly as well as young girls and women are bound to enter sex establishment as a commercial sex worker. Therefore, most of the time, an organized and wellconnected group of people engage with this profession to flourish the sex business and also snatch the lion share of those poor girl's income (Billah, Socio-Demographic Configuration of the Sex Labour Trade Bangladesh: Income Expenditure Portfolio of the Sex Workers, 2012). In the Prostitution business, there are multiple pushing factors of women involved in sex work, some are voluntarily including poverty, worse economic conditions, illness in the family, debt, sex for enjoyment, peer association, family neglect, domestic clashes, drug addiction in husbands and others are also involuntarily including forced rape, sexual assault, early marriages, trafficking, deceived by family, deceived by lover (Qayyum, Iqbal, Akhtar, Hayat, Janjua, \& Tabassum, 2013). This study represents that there has several observable reasons or factors for women to enter sex establishments.

Table-3: Reasons for entering to the sex establishment as CSWs

\begin{tabular}{|c|c|c|}
\hline Previous Work & $\begin{array}{l}\text { Present work tenure of } \\
\text { CSWs }\end{array}$ & $\begin{array}{l}\text { Reasons for entering to the sex establishment } \\
\text { as CSWs }\end{array}$ \\
\hline Domestic Worker & 4 years & Cheated by female Dalal \\
\hline Garments Worker & 8 Years & Deceived by Shopkeeper Who is a Male Dalal \\
\hline Housewife & More than 20 Years & Came here willingly to earn money \\
\hline No Work & 3 Years & Escaped from home and Sold by female Dalal \\
\hline Sex Worker & 18 Years & Born here and work here by her own will \\
\hline Domestic Worker & 12 years & $\begin{array}{l}\text { Quarreling with a family member and trapped } \\
\text { by a female Dalal }\end{array}$ \\
\hline Garments Worker & 6 Years & $\begin{array}{l}\text { Cheated by boyfriend and blamed herself for her } \\
\text { ego and anger }\end{array}$ \\
\hline Private Job & 8 Years & $\begin{array}{l}\text { Sold by her friend and wanted to earn more } \\
\text { money }\end{array}$ \\
\hline Sex Worker & 38 years & $\begin{array}{l}\text { Married off at an early age to a poor man, } \\
\text { forcefully sent by her husband }\end{array}$ \\
\hline Garments Worker & 2 Years & $\begin{array}{l}\text { Came here willingly with her sister to provide } \\
\text { financial support to her family }\end{array}$ \\
\hline
\end{tabular}

Note: Individual respondent mentioned the reasons behind their involvement

Most of them were engaging in different works including domestic work, garments job, private job and so on. Most tremendous thing is that two respondents were involved in another sex establishment in Bangladesh. Noteworthy is that there were also a housewife and an unemployed in the previous profession. One of the sex workers explained the reason for her entering the sex establishment in the following way:

One night I was coming from the village (Kishorganj) and I was brutally fell under the spell of one of my relatives who was also a female Dalal that was unknown to me and she assured me to provide a job for my survival and then sell me here. I am working here (Knadapara, Tangail) for 4 years. She added that I thought maybe I could find work as a domestic worker or in a garments factory.

This study shows a noticeable thing is that some respondents entered this profession accord of their own.

One of the respondents claimed: 
I came here because of my own free will. I am a married woman, however, my husband left me and married other women then I decided to come to Dhaka from Bagura for a job. At first, I was a domestic worker, at the same time I was searching for better opportunities and I joined a beauty parlor. In the beauty parlor, a woman offered me to enter a sex establishment and promised me to give a good amount of money. I come into the line of her and decided to enter the sex establishment. I have been here for more than 20 years.

Another respondent added that

I came here for being cheated on by my boyfriend and blamed myself for my ego and anger. Sometimes, I feel that why I am alive till now.

The reasons for entering the sex establishment mentioned by the sex workers themselves are diversified in nature and these are both voluntarily and involuntarily including: cheated by female Dalal, deceived by Shopkeeper who is a male Dalal, came willingly to earn money, escaped from home and sold by female Dalal, born here and work here by her own will, quarreling with a family member and trapped by a female Dalal, cheated by boyfriend and blamed herself for her ego and anger, sold by her friend and wanted to earn more money, married off at early age to a poor man, forcefully sent by her husband, came here willingly with her sister to provide financial support to her family. There are also remarkable variations of causation for entering sex establishment as 'Commercial Sex Workers' and for going to the sex establishment as 'Babus'. However, several studies according to the sex establishment staffs show that most of the clientele are regular clients. Further, there are also different types of clients such as 'romantic or friendship type' and also 'business type'. Besides, the studies demonstrate that men visit sex workers not only for sexual activities but also to fulfill certain psychological needs (Xantidis, Psych, \& P. McCabe, 2000). This study explores that there has several observable reasons or factors for male clients who are also attached to romantic of friendship type clients to enter the sex establishment as unbreakable babus in Bangladesh.

Table-4: Reason for going to a sex establishment as 'Babus'

\begin{tabular}{|c|c|c|}
\hline Occupation & Residence & Reason for going to a sex establishment as Babus \\
\hline $\begin{array}{l}\text { Grocery Owner } \\
\text { and politician }\end{array}$ & Tangail & (Inside the brothel) business is more profitable than the outsides \\
\hline Police Constable & Tangail & Excellent sexual partner in absence of wife \\
\hline $\begin{array}{l}\text { House rent } \\
\text { business }\end{array}$ & Tangail & $\begin{array}{l}\text { Low cost of getting a sexual partner and getting more } \\
\text { satisfaction }\end{array}$ \\
\hline Businessman & Tangail & Only for physical and sexual need \\
\hline Businessman & Tangail & Financially benefited by sex worker \\
\hline Police Constable & Tangail & $\begin{array}{l}\text { Duty zone was in the brothel, and became a habit to go to sex } \\
\text { worker }\end{array}$ \\
\hline NGO worker & Tangail & $\begin{array}{l}\text { Unsatisfied, insatiable, and also monotonous sexual relation with } \\
\text { wife }\end{array}$ \\
\hline Restaurant Owner & Tangail & Young sex workers give more pleasures than an old wife \\
\hline Shop keeper & Tangail & Fall in love with a sex worker \\
\hline Local politician & Tangail & $\begin{array}{l}\text { Physically unable to do sex and getting sexual satisfaction from } \\
\text { a sex worker }\end{array}$ \\
\hline
\end{tabular}

Note: Individual respondents mentioned the reasons

Babus are involved in diverse occupations as like as: grocery owner and politician, police constable, house rent business, businessman, NGO worker, restaurant owner, shop keeper and also a local politician. The unusual and exceptional thing is that the professions of police and NGO workers are used to go the sex establishment as 'Babus', notwithstanding, they are doing as protector and guard for people in general. According to babus, they said that there are diverse reasons for going to the sex establishment. For instance, one of the babus explained the reason for his going to the sex establishment in the following way: 
Usually, I feel sick to go to many girls (SW) for physical relations. I would like to do it now only with a special one for my physical safety. A babu does not marry the girls usually. By going to the same woman, again and again, an emotional attachment develops with her and thus I become permanent with her.

This study shows a noticeable thing is that some respondents go to a sex establishment for personal reasons, one of the respondents claimed:

I am not physically capable to do sex with my wife because of my age. My wife also getting aged and doesn't like to touch her body. However, I want to get sexual pleasure from her by kissing, touching, and seeing her nude body. I reckon that commercial sex workers never say 'No' and my permanent sex worker always ready to give me sexual satisfaction however I want.

Another respondent added that

My wife is always busy with children, household chores, and also maintains her office. She doesn't care about me as well as fulfilling my sexual desires in time. She always hurries in time of sexual intercourse; therefore, I don't get any sexual need from my wife. Over and above, I am more comfortable with the sex worker than my wife and the sex worker is bound to satisfy me because she is dependent for different support on me.

The reasons for going to the sex establishment mentioned by the unbreakable babus themselves are diversified in nature and all are voluntary including business is more profitable in an inside the sex establishment than the outsides, excellent sexual partner in absence of a wife, low cost of getting a sexual partner and getting more satisfaction, only for physical and sexual need, financially benefited by a sex worker, duty zone was in the sex establishment, and became a habit to go to sex worker, unsatisfied, insatiable and also monotonous sexual relation with wife, young sex workers give more pleasures than an old wife, fall in love with a sex worker, physically unable to do sex and getting sexual satisfaction from a sex worker and so on.

\section{Perception of Commercial Sex Workers (CSWs) about Babus and vice-versa}

The diversity of perception of the commercial sex workers and their babus mentioned by the respondents of the study conceives that visiting a sex worker may serve a wide variety of functions for the babu. Along with desiring for a sexual outlet, there are many kinds of perceptions about sex workers, for instance, emotional meanings, external reasons, cultural or fantasy or symbolic meanings, exotic and romantic meanings, and also both conscious and unconscious elements (Winick, 1962). Sex workers perceive and identify the variations of precise nature and degree of stigmatizations that they suffer: low grade, day to day abuse from individuals in the community; disrespectful and humiliating treatment from clients; and structural abuse by police and legal barriers preventing them from seeking justice and police assistance when they were victims of crime (Wong, Holroyd, \& Bingham, 2011). This study comprehends the perception of commercial sex workers cited by babus and also the perception of babus mentioned by sex workers. One of the sex workers cited that

My babu is a shopkeeper and we are staying together for almost two years. I have no problem with having a babu and he helps me in counting money, giving medical support, shopping, and all household work. I am not economically dependent on Babu rather sometimes; I give money him when he falls in trouble. He doesn't do any violence with me, she added. 
Table-5: Perception about Babus considered by CSWs

\begin{tabular}{ll}
\hline Case studies & Perception about Babus considered by CSWs \\
\hline CSW -1 & Not economically dependent on Babus, rather as an assistant \\
CSW -2 & Take into consideration as a husband \\
CSW -3 & Considered as a patron \\
CSW -4 & Regarded as a loving partner \\
CSW -5 & As a boyfriend \\
CSW -6 & Social safeguard and also emotional partner \\
CSW -7 & As a security guard \\
CSW -8 & Supposed to be a financial and psychological partner \\
CSW -9 & Considered as a husband \\
CSW -10 & Considered as a savior and a protector \\
\hline
\end{tabular}

Note: Individual respondents mentioned their own perceptions

However, commercial sex workers have been inquired about the babus to get some observations or actual feelings about how they perceive. They have shared different opinions about having fixed babus and also the babu culture in the sex industry. One of them commented that,

I had a Babu before but now he is no more. He had left me nearly four years. He married me and we have a daughter too. At the present I am suffering many problems without Babu as well as I am trying to make a babu again, I was fall in love with that babu. My babu never did any violent behavior with me rather he loved me so much. She emphasized that I considered him as a husband and my loving sexual partner.

Another sex worker shared her opinion that,

My babu lives outside the sex establishment and he has family in the outside society. He did not agree to marry me though I insisted on him over and over again. He used to take money from me in the time of his need. Furthermore, I have received a lot of benefits from him. I am dependent on him financially, socially and some of the time emotionally also. Sometimes he beats me mercilessly and inhumanely. Despite many of the turmoil or conflict between us we are having together for about nine years.

Therefore, this study explores that, there are diverse perceptions among the sex workers about their babus thrusting into that: not economically dependent, rather as an assistant; taking into consideration as a husband; considered as a patron; as a boyfriend; as a social safeguard and also emotional partner; as a security guard; supposed to be a financial and psychological partner; considered as a savior and a protector, etc. This study illustrates the perception of commercial sex workers mentioned by babus. One of the babus cited that

I was lived in Gazipur. One of his friends worked at Kandapara sex establishment and I heard that business is more profitable inside the sex establishment than the outsides, so I came here and started the business. I reckon that having a good relationship with the sex workers is beneficial for business, for this reason, I started to link with sex workers.

Another babu commented that

My wife lives in my hometown. She does not know anything about the sex worker's issue, but the sex worker knows about my wife. He opined that most of the Babu's have wives and have children in the outside society. I consider the sex worker as a beautiful sexual partner who paid so much attention to me. I have no problem 
staying with a sex worker. Though my wife is better than my partner (SW) I would like to give priority to my partner (SW) here for a secured, reliable, and refresher sex partner.

Furthermore, the unbreakable babus attached to the sex establishment at Kandarpara had been asked about the commercial sex workers to get some observations or actual feelings about how they perceive. They shared different opinions about having fixed sex workers. One of them commented that,

As a result of having sex workers, Babus' costs remain low and they get a good quality of facilities inside the sex establishment. My partner is only 25 years old and she does many things for me, for example, washing clothes, maintaining shops, having good food, mental supports and also free physical satisfactions and so on.

Table 6: Perception about CSWs considered Babus

\begin{tabular}{ll}
\hline Case studies & Perception of CSWs by Babus \\
\hline Babu-1 & As a true friend and a good mental supporter \\
Babu-2 & A liberal and beautiful sexual partner who paid so much \\
& attention to me \\
Babu-3 & Considered as a cheaper sexual partner \\
Babu-4 & Considered as comely and good company \\
Babu-5 & As a good income source and reliable financial support \\
Babu-6 & Secured, reliable, and refresher sex partner \\
Babu-7 & As an experienced and mature sexual partner \\
Babu-8 & As a Second wife \\
Babu-9 & As a love partner \\
Babu-10 & Secured, reliable, and refresher sex partner \\
\hline
\end{tabular}

Note: Individual respondent mentioned their perceptions

The remarkable and also interesting thing is that babus consider commercial sex workers not only as sexual or physical satisfaction but also as a second wife. One of the respondents has cited in the following way:

I am a police constable. When I was here as a duty constable in this area, I met a sex worker who was very polite and humble as well as very beautiful. We talked several times with each other and shared our feelings, personal life as well as a different matter of our sorrows. Suddenly I discovered that I fall in love with her, and then I was starting to go the sex establishment only for her. I married her and considered her as my second wife. My first wife is unknown to her and to be honest, I wish that my wife would unable to know the real fact because I have two children.

On top of that, this study explores that, there are diverse opinions or observations as well as perceptions among the babus about their fixed sex partners at sex establishment including: as a true friend and a good mental supporter; a liberal and beautiful sexual partner who paid so much attention to me; considered as a cheaper sexual partner; considered as comely presentable and also a good company; as a good income source and reliable financial support; secured, reliable and refresher sex partner; as an experienced and mature sexual partner; as a second wife and as a love partner and so on.

\section{Discussion}

Sex work is a complex issue. Some studies about sex work have focused mainly on the risk factors, some studies have emphasized how the people who work with female sex workers involved in sex work perceive the impacts that sex work has on these women's life paths (Tremblay, Lanctot, \& Couvrette, 2020), few studies examine stigma in this context from the perspective of the sex workers themselves (Wong, Holroyd, \& Bingham, 2011), few studies examine the factors associated with sex 
work-related stigma along with two perceived stigma domains: the community and family (Rael, 2015). This study has tried to explore the complete picture as well as for a better understanding about the commercial sex workers, their relationship with babus, the reason of entering to sex establishment of commercial sex workers, the cause of going to the sex establishment of the babus and to explore the perceptions of the babus about CSWs and vice-versa in Bangladesh.

The study shows that commercial sex workers are working as with only one identified as 'prostitution' lived in sex establishment at Kandapara and all respondents of CSWs are female engaging sexual practice and activities by selling their body in exchange of money. Furthermore, Babus have been conceptualized as more than clients in a sex establishment and have been claimed by the CSWs as an unauthorized husband, intimate partner, lovers, and also fixed and regular loving customer. Besides, all respondents of babus are unbreakable, live outside the sex establishment and all are male respondents.

The preliminary finding from this study is to know the socio-economic and demographic profile of the commercial sex workers and babus in Bangladesh. The notable thing in this research is that young sex workers are more prevalent and imperious than the senior sex worker. The unusual matter here is that two unmarried respondents have one female child and because of their female child they get extra priority with many facilities by Shordarni (Sex worker's leader). Furthermore young age unmarried sex workers with having no children earn more money than more senior married with having children. Remarkable diversity can also be found that relatively educated sex workers earn a good amount of money than illiterate sex workers.

The conflicting character in the study shows relatively older age attaches a sex establishment as 'Babus' than younger. Therefore, literate persons are more attached to unbreakable Babu Culture than illiterate. The observable issue here is that married babus with having children and a good amount of monthly income is more attached to sex workers than unmarried babus and low monthly income. Hence, the socio-demographic and economic backgrounds of the respondents differ remarkably to enter a sex establishment.

One of the main themes of the study is to investigate the underlying reasons for entering a sex establishment as 'Commercial Sex Worker' and as 'Babus'. The reasons for entering a sex establishment mentioned by the sex workers themselves are diversified in nature and these are both voluntarily and involuntarily in nature. Some commercial sex workers are cheated by female Dalal, deceived by Shopkeeper who is a male Dalal; Some come here willingly to earn money; few are escaped from home and sold by female Dalal; most unexpected thing here is that very few are born here and work here by her own will, quarreling with a family member and cheated by a boyfriend are the other reason and some blame themselves for their ego and anger, the cruel truth is associated with married off at early age to a poor man and forcefully sent my husband, some came here willingly with her sister to provide financial support to her family. The reasons for going to a sex establishment mentioned by the unbreakable babus themselves are diversified in nature and all are voluntary including business is more profitable in an inside the sex establishment than the outsides, excellent sexual partner in absence of a wife, low cost of getting a sexual partner and getting more satisfaction, only for physical and sexual need, financially benefited by a sex worker, duty zone was in the sex establishment, and became a habit to go to sex worker, unsatisfied, insatiable and also monotonous sexual relation with wife, young sex workers give more pleasures than an old wife, fall in love with a sex worker, physically unable to do sex and getting sexual satisfaction from a sex worker and so on.

The findings also open a new window on a subject that the perception of commercial sex workers cited by babus and also the perception of babus mentioned by sex workers. The diverse perceptions among the sex workers about their babus are that: not economically dependent, rather as an assistant; taking into consideration as a husband; considered as a patron; as a boyfriend; as a social safeguard and also emotional partner; as a security guard; supposed to be a financial and psychological partner; considered as a savior and a protector, etc. This study illustrates the perception of commercial sex workers mentioned by babus. Furthermore, unbreakable babus have shared different opinions about having fixed sex workers. The remarkable and also interesting thing is that babus consider commercial 
sex workers not only as sexual satisfaction but also as a second wife. On top of that, this study explores that, there are diverse perceptions among the babus about their fixed sex partners at the sex establishment including: as a true friend and a good mental supporter; a liberal and beautiful sexual partner who paid so much attention to me; considered as a cheaper sexual partner; considered as comely presentable and also a good company; as a good income source and reliable financial support; secured, reliable and refresher sex partner; as an experienced and mature sexual partner; as a second wife and as a love partner and so on.

\section{Further Implications and Limitations}

The sex workers' related studies are themselves very sensitive and complex issues in society. This study explores the commercial sex workers, and its relationship and connectivity with the unbreakable babu culture in Bangladesh. The remarkable variations have been observed in the study based on socio-demographic and economic status; diverse causation for the attachment with sex establishment both of CSWs and babus; and also multidimensional perceptions among themselves. The study is not beyond limitation. The first and foremost limitation is that the research may fail to measure quantitatively that could have represented the complete picture of the research. Another limitation is that the respondents who are attached to sex establishment may provide wrong information that is impossible to verify and finally, it can be assumed that the respondents who are interviewed in the study are diversified regarding their socio-demographic and economic backgrounds might have provided different perspectives.

Besides, the study has tried to show the relationship between babus and CSWs, but it may be less observant about the internal cohesion, health status, sigma, different facilities also the internal condition of the environment of sex establishment. Emphasizing to recover the conditions of commercial sex workers should be major concerns for Bangladesh that are being started in a bid to put in (Candela \& Aldama, 2015). Despite these limitations, the result of the present study has considerable importance as well as the findings may provide a cornerstone for doing further study in these research issues.

A future study should be conducted since there are different classifications of commercial sex workers; nevertheless, only female CSWs and male babus have been investigated with their intimate relationship of babus (Xantidis, Psych, \& P. McCabe, 2000). However, major attention is needed to do more research on male and transgendered sex workers, female intimate and fixed clients, and so on (Weitzer, 2005).

One of the babus suggest with an optimistic view that

Babu can improve the condition of sex workers. If they marry them and take them into the main society, it may be good for every female sex worker.

In correspondence with the statement, the research proposes that the attitudes and perceptions of the common people towards commercial sex workers should be changed to enhance their vulnerable situation. It is high time for the government to give more attention to this issue as the future of our country rests in today's children and proper steps, policies, and practices should be taken by the government and correctional institutions and also social NGOs concerning the safety and well-being of commercial sex workers (Haque, Haque, \& Muniruzzaman, 2020). In a word, the findings of the study have drawn a new insight for exploring the clear conceptualization about commercial sex workers, their babus as well as the causation of entering to a sex establishment and also the diverse perceptions that may help for further implications. 


\section{Conclusion}

To summarize, in this research, female CSWs with only one identified as 'prostitution' in Bangladesh are closely related to their babus with characterized as intimate, unauthorized husband and fixed clients. Though the relationship between commercial sex workers and babus itself a conceptual and also complicated issue, it has been tried in this research to evaluate the relationship from diverse perceptions. Already it has been noted that all CSWs are female and most of them are attached with babus. Remarkable variations and a close relationship among respondents to the causation of connectivity with sex establishment have been found in terms of their socio-demographic and economic backgrounds. There are diversified reasons for entering a sex establishment of CSWs and babus in where for CSWs, reasons are both voluntarily and involuntarily in nature and most notable thing are that all are voluntary on behalf of babus.

There are diverse opinions as well as perceptions among the CSWs and babus about their fixed sex partners. The tremendous and unusual issue is that CSWs undertake babus as their unauthorized husband; and conversely, the remarkable and interesting thing is that babus consider CSWs not only as sexual companion but also as a second wife. The findings of this research have opened a new window on this perplexing and impressionable issue that may assist the researcher in their further investigation about this field.

\section{References}

Banerjee, S. (1993, November 6). The 'Beshya' and the 'Babu': Prostitute and Her Clientele in 19th Century Bengal. Economic and Political Weekly, 2461-2472.

Billah, M. (2012). Socio Demographic Configuration of the Sex Labour Trade Bangladesh: Income Expenditure Portfolio of the Sex Workers. International Journal of Sustainable Development .

Billah, M. (2012). Socio Demographic Configuration of the Sex Labour Trade in Bangladesh: Income Expenditure Portfolio of the Sex Workers. OIDA International Journal of Sustainable Development , 4 (No.9), 51-62.

Candela, M., \& Aldama, Z. (2015, February 23). Retrieved July 7, 2020, from The Diplomate: https://thediplomat.com/2015/02/the-brothels-of-bangladesh/

Farlex. (2009). Retrieved 9 3, 2020, from Medical Dictionary: https://medicaldictionary.thefreedictionary.com/commercial+sex

Haque, I. E., Haque, M., \& Muniruzzaman, M. (2020). Young Age and Crime in Society: A Study on Youth Prisoners in Bangladesh. International Journal of Social Science Studies, 8 (3).

Karim, S. (2004). Exploring the Household Compositions of Female Sex- workers in Brothels: Daulatdia, A Case Study. BRAC University Journal, 33-48.

Lavrakas, P. J. (2008). Encyclopedia of Survey Research Methods. Retrieved 09 23, 2020, from Sage Reserch Method: https://methods.sagepub.com/reference/encyclopedia-of-survey-researchmethods/n419.xml\#: :text=A\%20purposive\%20sample\%2C\%20also\%20referred,be\%20represe ntative $\% 20$ of $\% 20$ the $\% 20$ population.

Mahtab, N., Haque, T., Khan, I., Islam, ,. M., \& Wahid, I. B. (2018). Handbook of Research on Women's Issues and Rights in the Developing World. United State of America: IGI Global Book series Advance in Electronic Government, Digital Devide, and Regional Development.

Overs, C. (2002). Retrieved 9 3, 2020, from World Heath Organization: https://www.who.int/hiv/topics/vct/sw_toolkit/115solution.pdf

Qayyum, S., Iqbal, M. M., Akhtar, A., Hayat, A., Janjua, I. M., \& Tabassum, S. (2013). Causes and Decision of Women's Involvement into Prostitution and it's Consequences in Punjub, Pakistan. Academic Research International, 4 (5).

Rael, C. T. (2015). Perceptions of Sex Work-Related Stigma in Female Sex Workers from the Dominican Republic: Implications for HIV Interventions. Sexuality \& Culture, 674-684.

Sinha, S. (2015). Reasons for Women's Entry into Sex Work: A Case Study of Kolkata, India. Sexuality \& Culture: An Interdisciplinary Quarterly, 19 (DOI 10.1007/s12119-014-9256-z). 
DOI: https://doi.org/10.47405/mjssh.v6i8.913

Tremblay, L. M., Lanctot, N., \& Couvrette, A. (2020, March 12). The hopelessness effect: Counsellors' perceptions of their female clients involved in sex work in Canada. Health and Social Care in the Community.

Weitzer, R. (2005). New directions in research on prostitution. Crime, Law \& Social Change, 221235.

Winick, C. (1962). Prostitutes' Clients' Perception of the Prostitutes and of Themselves. International Journal of Social Psychiatry, 8 (4), 289-297.

Wong, W. C., Holroyd, E., \& Bingham, A. (2011). Stigma and sex work from the perspective of female sex workers in Hong Kong. Sociology of Health \& Illness, 33 (1), 50-65.

Xantidis, L., Psych, M., \& P. McCabe, M. (2000). Personality Characteristics of Male Clients of Female Commercial Sex Workers in Australia. Archives of Sexual Behavior, 29 (2). 